\title{
Dislocation of the proximal tibiofibular joint, do not miss it
}

\author{
Alexander FY van Wulfften Palthe, Linda Musters, Remko JA Sonnega, \\ Hans A van der Sluijs
}

Department of Orthopaedic Surgery, VU University Medical Center, Amsterdam, The Netherlands

\section{Correspondence to} Dr Hans A van der Sluijs, ja.vandersluijs@vumc.nl

Accepted 4 November 2015
CrossMark

To cite: van Wulfften Palthe AFY, Musters L, Sonnega RJA, et al. BMJ Case Rep Published online: [please include Day Month Year] doi:10.1136/bcr-2014207875

\section{SUMMARY}

We present a case of a 45-year-old woman with a right proximal tibiofibular dislocation she sustained after a fall during roller skating. Anteroposterior and lateral radiographs confirmed the diagnosis; there were no other injuries. The dislocation was reduced by direct manipulation after intra-articular infiltration, in our emergency department. The patient was treated with a long, non-weight bearing leg cast for 1 week. After 4 weeks, she had no pain and a full range of motion of the knee.

\section{BACKGROUND}

A traumatic dislocation of the proximal tibiofibular joint is a rare and often missed diagnosis. Mild clinical presentation and subtle abnormalities on radiographs make it a challenging diagnosis. Treatment is often simple if the pathology is understood. We present a case from our hospital and an overview of this diagnosis that should be considered in all cases of lateral knee pain after trauma.

\section{CASE PRESENTATION}

A 45-year-old woman presented to the emergency department of our hospital with a painful right knee after she fell during roller-skating. Her knee was twisted with force while it was in a position of about $90^{\circ}$ flexion. She reported pain on the lateral side of her knee and inability to bear weight. Her medical history showed no relevant diagnoses.

\section{INVESTIGATIONS}

Physical examination showed a mild lateral swelling, with tenderness at the site of the proximal tibiofibular joint. Range of motion was decreased and painful. Neurological examination of the leg showed no abnormalities. A radiograph of the right knee showed an anterolateral dislocation of the proximal fibula (figure 1).

\section{DIFFERENTIAL DIAGNOSIS}

Many other diagnoses are possible in the case of lateral knee pain after trauma. Most important are fracture, ligamentous injury and meniscal tear. Other osseous or ligamentous injuries were excluded by careful examination of the radiographs and re-evaluation of the patient after repositioning the fibular head, which revealed almost no more pain and a stable knee. Other injuries were excluded 1 week after the trauma, when the patient reported having a pain-free knee with full range of motion.

\section{TREATMENT}

After intra-articular infiltration of anaesthetic in the proximal tibiofibular joint, the fibular head was reduced by direct manipulation in anterior to posterior direction with the knee in $90^{\circ}$ of flexion. A radiograph following reduction showed an anatomical proximal tibiofibular joint (figure 2). The patient was discharged with a long leg cast, non-weight bearing.

\section{OUTCOME AND FOLLOW-UP}

After 1 week, the cast was removed and the patient started with protected weight bearing. After 4 weeks, she was able to bear full weight, and had a full range of motion and no pain.

\section{DISCUSSION}

Proximal tibiofibular dislocation is a rare diagnosis, consisting of $<1 \%$ of all knee injuries. ${ }^{1}$ With mild symptoms and minimal abnormalities on radiographs, this is an often missed diagnosis. ${ }^{1}$

The mechanism is that of a rotation of the lower leg while the knee is at $90^{\circ}$ flexion. $^{2}$ Common symptoms are pain or tenderness along the lateral side of the knee and a painful, limited range of motion with inability to bear weight. In some cases, patients may have heard a 'plop' at the time of the trauma. Sometimes, examination of the knee

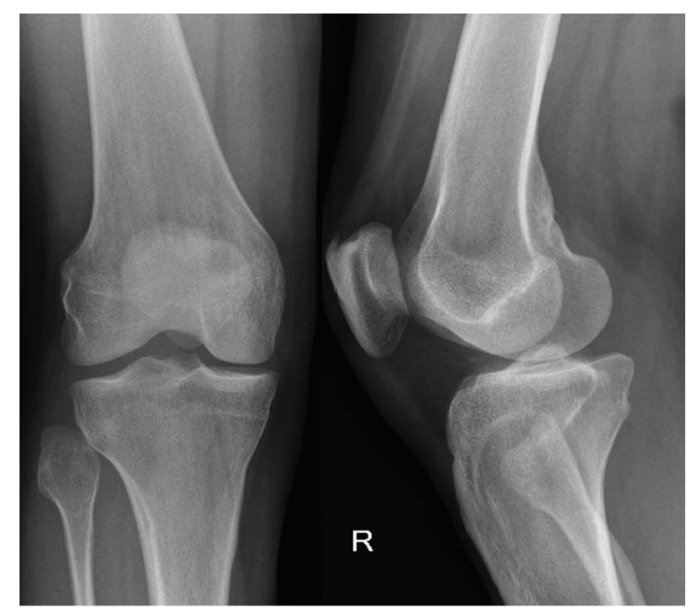

Figure 1 Radiograph of the right knee showing an anterolateral dislocation of the proximal fibula. On the anteroposterior radiograph, the fibular head is located too far laterally and there is insufficient overlap with the lateral margin of the proximal tibia. On the lateral radiograph, the fibular head is located anteriorly from the joint line of the proximal tibiofibular joint. 


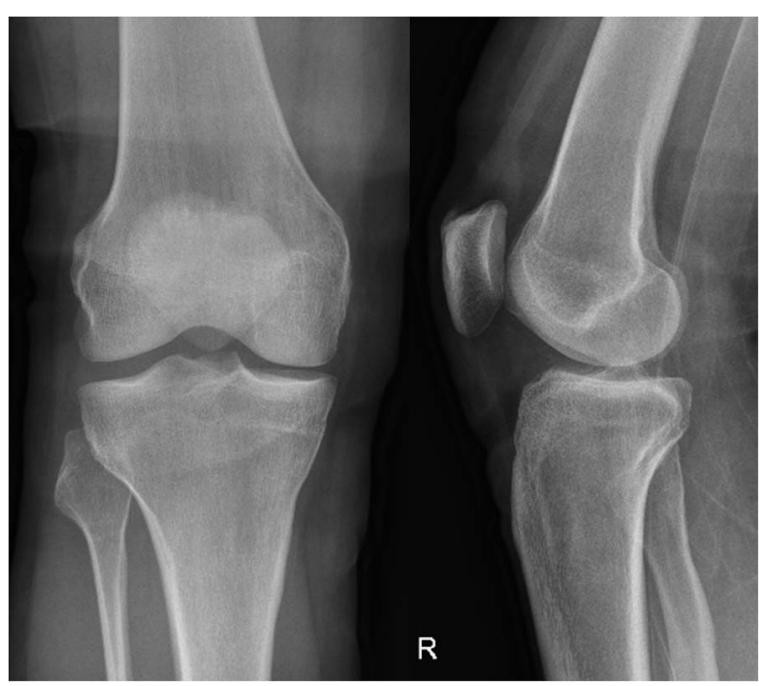

Figure 2 Radiograph of the right knee after relocation of the proximal fibula, showing an anatomical proximal tibiofibular joint. There is sufficient overlap of the fibular head with the lateral margin of the proximal tibia on the anteroposterior radiograph. On the lateral radiograph the fibular head is located in the correct position with respect to the joint line of the proximal tibiofibular joint.

will reveal a prominence in the fibular head area. These symptoms can be very subtle though, so it is important to compare the position of the fibular head with that on the healthy side. The normal location of the fibular head is just distal and posterior of the lateral joint line of the knee. In cases of peroneal nerve neuropraxia, symptoms of inability to dorsiflex the foot or sensory loss of the dorsal surface of the foot may occur. The abnormalities on radiographs can be very subtle, and therefore difficult to detect. On a normal anteroposterior radiograph of the knee, the fibular head should be located below the lateral joint line and overlap the lateral margin of the proximal tibia; on a normal lateral radiograph, the fibular head is located just posterior to the proximal tibia. The joint line of the tibiofibular joint is often difficult to identify because of overlap of the tibia. If a radiograph does not meet these criteria, one should be suspicious of the diagnosis, 'tibiofibular dislocation'. In case of doubt, an additional radiograph of the healthy knee can be useful, since it is likely that a difference will be noticed between the two radiographs regarding the position of the fibular head. ${ }^{3}{ }^{4}$ One should be wary of the fact that an incorrectly taken radiograph may make it difficult to find or exclude the diagnosis, since a radiograph of a rotated knee will project the position of the fibular head differently. If doubt still exists, a CT scan is the modality of choice to confirm or exclude the diagnosis.

Proximal tibiofibular dislocation is divided into four types, as described by Ogden, ${ }^{5}$ in which the direction of displacement of the proximal fibula is key (figure 3 ).

Type $\mathrm{I}$ is a laxity of the tibiofibular joint, without pure dislocation. This is most common during growth and is self-limiting.

Type II is an anterolateral dislocation, present in $85 \%$ of proximal tibiofibular dislocation cases. The mechanism of trauma is internal rotation and plantar flexion of the foot, with exorotation and flexion of the knee. ${ }^{67}$

Type III is a posteromedial dislocation, most often caused by direct trauma to the proximal fibula.

Type IV is a superior dislocation caused by high impact trauma and is often accompanied by other pathology of the knee.

Injury to the peroneal nerve is most often seen in type II dislocations, however, it has been described in all types.

Prompt treatment prevents long-term complications such as lateral knee pain or instability of the proximal tibiofibular joint that might result in the inability to perform daily activities or sports. Treatment of the dislocation can be performed by closed or open reduction. A first attempt to closed reduction can be performed in the emergency department. Reduction of the proximal fibula is performed with the knee in $90^{\circ}$ of flexionbecause in this position, the joint is least stable since the joint
Figure 3 Classification of proximal tibiofibular joint dislocations as described by Ogden. Type I: laxity of the joint, the normal anatomy is shown. Type II: anterolateral dislocation. Type III: posteromedial dislocation. Type IV: superior dislocation.
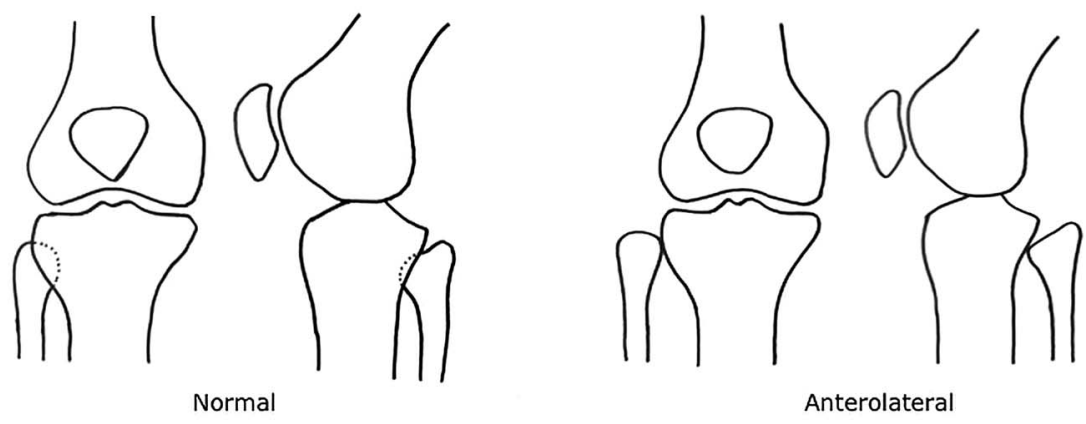

Anterolateral
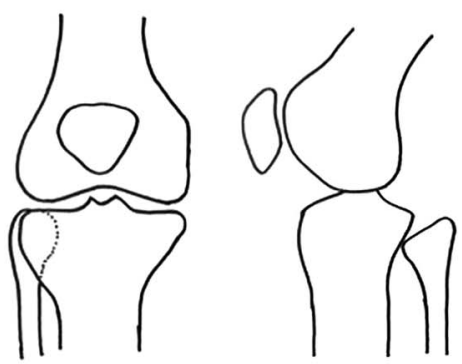

Posteromedial

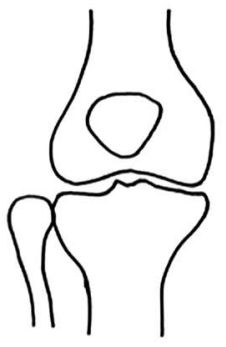

Superior 
capsule and ligaments are not taut-by applying direct pressure to the proximal fibula in the correct direction, depending on the type of dislocation. The use of intra-articular anaesthesia can be considered, we use lidocaine for intra-articular analgesia, but other types can be used. When successful, there is an audible 'click' sound. After reduction, one should examine function and stability of the knee joint and proximal tibiofibular joint. Stability of the proximal tibiofibular joint is examined by trying to translate the fibular head from anterior to posterior while the knee is at $90^{\circ}$ of flexion. The amount of translation should not be more than on the healthy side. Also, the peroneal nerve should be examined by testing the ability to dorsiflex the foot, and sensory function of the dorsal surface of the foot.

Whenever closed reduction is unsuccessful in an acute case, one should choose open reduction. Open reduction always requires internal fixation to provide stability to the joint that is compromised since stabilising ligaments and joint capsule are cut during the surgical approach. Many techniques have been described; the options are temporary fixation, permanent arthrodesis and soft tissue reconstruction. Since permanent arthrodesis often leads to ankle pain, temporary screw fixation or soft tissue reconstruction would be our first choice. ${ }^{1}{ }^{7}$ In our opinion, closed reduction by direct manipulation should always be attempted in an acute case, and open reduction should be reserved for acute cases in which reduction by direct manipulation has failed. We believe conservative treatment should be reserved only for cases of late presentation or chronic dislocation.

Aftercare treatment should be chosen with respect to comorbidities, type of treatment, concomitant injuries and pain. Since the proximal tibiofibular joint is a primarily stable joint if there is no osseous damage, we opted for 1 week of rigid immobilisation in a cast to provide stability for the soft tissues to heal. Use of a brace with controlled range of motion is also a viable option, with possibly less chance of joint stiffness, muscle wasting and deep vein thrombosis. However, the patient must be well instructed and compliant. Taking these considerations into account, we felt it was safe to let our patient start with protected weight bearing and to progress to full weight bearing over a period of 4 weeks.

Most patients do not have any residual symptoms after a dislocation of the proximal tibiofibular joint and adequate treatment. However, there is very little literature on the long-term outcome. 89

Dislocation of the proximal tibiofibular joint is a rare diagnosis and can easily be missed. One should consider this diagnosis in every case of traumatic lateral knee pain and pay careful attention to how the patient describes the trauma. Physical examination should include addressing the fibular head and proximal tibiofibular joint. Careful examination of the radiographs is essential and, in case of doubt, one should compare them with radiographs of the healthy knee. In every case of acute dislocation, closed reduction should first be attempted.

\section{Learning points}

- Dislocation of the proximal tibiofibular joint is a rare diagnosis that is easily missed and should be considered.

- Treatment is simple if the pathology is understood.

- Long-term complications in the form of pain and/or instability occur and, when not treated, this may lead to inability to perform daily activities or sports.

- An attempt at closed reduction by direct manipulation, before surgery is considered, is advised.

Contributors AFYVWP and RJAS were responsible for conception and design, and acquisition of the data. AFYVWP and LM were responsible for analysis and interpretation of the data, and drafting the article. AFYvWP was responsible for drawings; and revising the manuscript and responding to comments from the other authors. All the authors were responsible for revising the article critically for important intellectual content, and final approval of the version published.

Competing interests None declared.

Patient consent Obtained.

Provenance and peer review Not commissioned; externally peer reviewed.

\section{REFERENCES}

1 Seymortier van $\mathrm{P}$, Ryckaert $A$, Verdonk $P$, et al. Traumatic proximal tibiofibular dislocation. Am J Sports Med 2008;36:793-8.

2 Horan J, Quin G. Proximal tibiofibular dislocation. Emerg Med J 2006;23:e33.

3 Keogh P, Masterson E, Murphy B, et al. The role of radiography and computed tomography in the diagnosis of acute dislocation of the proximal tibiofibular joint. $\mathrm{Br}$ J Radiol 1993;66:108-11.

4 Voglino JA, Denton JR. Acute traumatic proximal tibiofibular dislocation confirmed by computed tomography. Orthopaedics 1999;22:255-8

5 Ogden JA. The anatomy and function of the proximal tibiofibular joint. Clin Orthop Relat Res 1974;101:192-7.

6 Ellis C. A case of isolated proximal tibiofibular joint dislocation while snowboarding. Emerg Med J 2003;20:563-4.

7 Laing AJ, Lenehan $B$, Ali $A$, et al. Isolated dislocation of the proximal tibiofibular joint in a long jumper. Br J Sports Med 2003;37:366-7.

8 Aladin A, Lam KS, Szypryt EP. The importance of early diagnosis in the management of proximal tibiofibular dislocation: a 9- and 5-year follow-up of a bilateral case. Knee 2002;9:233-6.

9 Nieuwe Weme RA, Somford MP, Schepers T. Proximal tibiofibular dislocation: a case report and review of literature. Strategies Trauma Limb Reconstr 2014;9:185-9.

Copyright 2015 BMJ Publishing Group. All rights reserved. For permission to reuse any of this content visit

http://group.bmj.com/group/rights-licensing/permissions.

BMJ Case Report Fellows may re-use this article for personal use and teaching without any further permission.

Become a Fellow of BMJ Case Reports today and you can:

- Submit as many cases as you like

- Enjoy fast sympathetic peer review and rapid publication of accepted articles

- Access all the published articles

- Re-use any of the published material for personal use and teaching without further permission

For information on Institutional Fellowships contact consortiasales@bmjgroup.com

Visit casereports.bmj.com for more articles like this and to become a Fellow 